\title{
Taking Responsibility First: A Survey of Social Responsibility of Small and Medium-sized Retail Enterprises in Beijing - Based on the Data of Four Districts
}

\author{
Haitao Zhao \\ University of International Business and Economics, No.10 Huixin East Street, Chaoyang District, Beijing
}

\begin{abstract}
Based on the logical framework of "Cognition and Motivation-Behavior-Performance", this paper investigates the cognition and driving factors of managers of small and medium-sized enterprises to corporate social responsibility, and summarizes four behaviors of fulfilling social responsibility according to the Guide to Social Responsibility of Small and Medium-sized Enterprises in China, including employees, market, environment and community, and measures the corporate performance from three aspects: economy, society and environment. The results show that: (1) Social responsibility cognition has a significant positive effect on the fulfillment of social responsibility, and has a greater impact on the fulfillment of employees and market responsibilities; (2) The driving force of social responsibility has no significant effect; (3) Employees' and environmental responsibilities have a positive impact on corporate performance, while market responsibilities and social responsibilities have no significant impact on corporate performance.
\end{abstract}

Keywords: Social responsibility, Small and medium retail enterprises, Structural equation, Performance.

\section{Introduction}

With the concept of sustainable development deeply rooted in people's hearts, people are paying more attention to social responsibility as well as economic interests. Recently, the negative social events such as the living environment and privacy of the famous apartment brand "ziroom" and the longevity biological vaccine have appeared one after another, which touched the pain point of the public and aroused the public's concern about social responsibility. Social responsibility will not only have a greater impact on society, but also achieve corporate profitability by influencing social responses. Therefore, many scholars and investors have begun to attach importance to the concept of corporate social responsibility.

At present, the investigation of social responsibility mainly focuses on large enterprises and listed companies, while the investigation of social responsibility of small and medium-sized enterprises is not much. However, the data shows that small and medium-sized enterprises account for more than $99 \%$ of the total number of enterprises in China, creating about $60 \%$ of the total economic output, $50 \%$ of fiscal revenue and providing nearly $80 \%$ of urban jobs. Firstly, at present, most of the researches in China focus on the influence of large enterprises on social development, while the influence of small and medium-sized enterprises is underestimated. Secondly, in all industries, small and medium-sized retail enterprises, as social cells, play an important role in the lives of citizens and the process of social reproduction. Data show that by the end of 2020, the total retail sales of social consumer goods in Beijing reached 12.84 trillion yuan, and the GDP of wholesale and retail industry was 275.89 billion yuan, accounting for about $7.6 \%$ of Beijing's total GDP. So what is the fulfillment of social responsibility of small and medium-sized retail enterprises?
What are the factors that affect China's small and medium-sized retail enterprises to fulfill their social responsibilities?

In view of this background, this paper focuses on small and medium-sized retail enterprises through questionnaire survey, and investigates and analyzes the social responsibility of small and medium-sized retail enterprises in Beijing. The research aims to understand the cognition, driving factors and performance of corporate social responsibility, and to explore whether there is a relationship between the performance of corporate social responsibility and corporate performance. Especially in the research on the pre-factors of corporate social responsibility, previous studies usually conducted research on one of them, "cognition-behavior" or "driver-behavior", and rarely studied both at the same time. This article finds current problems through analysis, and proposes corresponding countermeasures to promote our SMEs to better fulfill their social responsibilities, so as to realize the sustainable development of SMEs.

\section{Theoretical Background and Framework}

Entrepreneurs, as the leaders of enterprises and the makers of strategic decisions, play a key role in the future development of enterprises. Enterprise managers' awareness of corporate social responsibility will inevitably have an impact on corporate social responsibility behavior, and then affect corporate performance[1]. For example, work experience and age differences have a greater impact on social responsibility and environmental responsibility attitude than on economic responsibility[2]. Therefore, we can put forward:

Hypothesis 1: There is a significant positive correlation between managers' social responsibility cognition and corporate social responsibility performance. 
Hypothesis 2: There is a significant positive correlation between the driving force of corporate social responsibility and the fulfillment of corporate social responsibility.

Based on the empirical research of KLD database and company data, scholars found that there is a positive correlation between corporate social responsibility and corporate performance [3]. By analyzing the data of listed companies in Shanghai and Shenzhen stock markets, the research pointed out that social responsibility has been paid attention to by listed companies in China, and there is a significant positive correlation between corporate social responsibility and financial performance [4]. Corporate social responsibility is conducive to establishing corporate image, producing advertising effect, enhancing the credibility of enterprises, establishing good relations with customers and employees, enhancing the attraction to talents and improving the market competitiveness of enterprises [5]. Therefore, this paper proposes:

Hypothesis 3: The fulfillment of social responsibility has a significant positive correlation effect on enterprise performance.

Further put forward the hypothesis:

H3a: Employee responsibility fulfillment has a significant positive correlation effect on enterprise performance.

H3b: The fulfillment of market responsibility has a significant positive correlation effect on enterprise performance.

H3c: The fulfillment of environmental responsibility has a significant positive correlation effect on enterprise performance.

H3d: community responsibility fulfillment has a significant positive correlation effect on enterprise performance.

Based on the above assumptions, this paper establishes the following model according to the logic of "social responsibility cognition + drive - social responsibility fulfillment - corporate performance" [6-10].

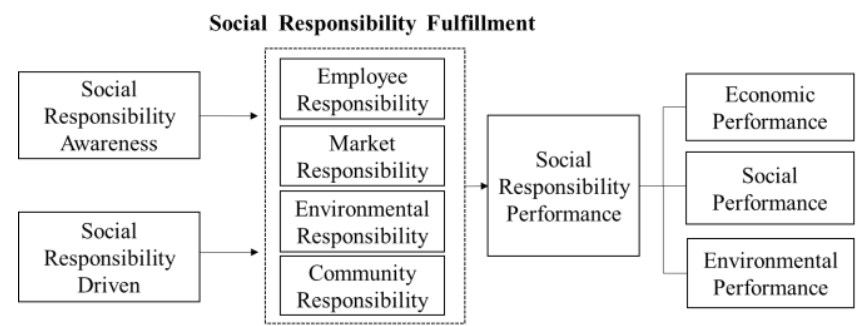

Figure 1: Cognition + Drive - Fulfillment - Performance research framework

\section{Research and Design}

\subsection{Methods}

Firstly, this paper collects all kinds of information of small and medium-sized enterprises through questionnaire survey; Secondly, the agent variables to be studied are summarized by factor analysis method. According to the different setting of questionnaire questions, exploratory factor analysis is used for social responsibility cognition and driving factors, while confirmatory factor analysis is used for social responsibility performance and enterprise performance. Finally, the structural equation is used to test the fitting degree and parameters of the model relationship to get the final conclusion.

\subsection{Questionnaire Design}

The questionnaire includes fill-in questions and multiple-choice questions. Multiple-choice questions mainly include three contents: basic information of participants, basic information of enterprises, and information related to corporate social responsibility.

The basic information of the participants mainly includes gender, age, education level, working years, and management level; the basic information of the company, including the duration of existence, the nature of the company, and the scope of business, are obtained by manual inquiries on the company.

Corporate social responsibility perceptions, driving factors, responsibility fulfillment and corporate performance are measured in the form of a Likert 5-level scale, where 1 means "completely disagree", 2 means "disagree", 3 means "fair", and 4 means "Agree", 5 means "completely agree", the respondent will score each question according to the actual situation of the company, the specific situation is shown in the table1 below.

Table 1: Questionnaire project

\begin{tabular}{|c|c|c|c|}
\hline Part & Main & Detail & Number \\
\hline Part I & $\begin{array}{c}\text { Personal } \\
\text { information }\end{array}$ & $\begin{array}{c}\text { Gender, age, } \\
\text { education, working } \\
\text { years and management }\end{array}$ & Q1 Q4 \\
\hline Part II & Cognition & $\begin{array}{c}\text { Attitude and } \\
\text { significance }\end{array}$ & Q6-1 Q6-8 \\
\hline Part III & Driving Factors & $\begin{array}{c}\text { External and internal } \\
\text { appeal factors }\end{array}$ & Q7-1 Q7-7 \\
\hline Part IV & Implementation & $\begin{array}{c}\text { Employee, market, } \\
\text { environmental, } \\
\text { community }\end{array}$ & Q8-1 Q8-14 \\
\hline Part V & Performance & $\begin{array}{c}\text { Economic, } \\
\text { environmental, } \\
\text { social performance }\end{array}$ & Q9-1 Q9-12 \\
\hline
\end{tabular}

\subsection{Sample Introduction}

A questionnaire survey was conducted on 248 retail SMEs in the four districts of Xicheng, Haidian, Daxing, and Fangshan through field visits, and 198 questionnaires were obtained. The questionnaire judged the validity of the questionnaire by setting up before and after confirmatory questions, and excluding inconsistent questionnaires, 162 valid questionnaires were obtained.

The samples are more evenly distributed among different regions, with companies in the city center and suburban areas accounting for roughly half of them. Among them, the most selected samples were Xicheng District, which reached $38.51 \%$, followed by Daxing District, which reached $30.43 \%$, 
followed by Fangshan District, which reached 18.63\%, and Haidian District had the least sample size, accounting for only $12.42 \%$.

In the distribution of the nature of enterprises, $53.42 \%$ of enterprises are limited liability companies, sole proprietorship of natural persons and sole legal persons accounted for $16.77 \%$ and $10.56 \%$ respectively, individual industrial and commercial households accounted for $12.42 \%$, and joint-stock limited enterprises accounted for only 6.83 . In general, the proportion of limited liability companies significantly exceeds that of joint stock companies, and the number of sole proprietorships is also greater than the number of joint ventures. Nearly half of the companies in the sample belong to food, accounting for $49.38 \%$, followed by hardware accounting for $18.52 \%$. The remaining industries have a relatively small proportion and are relatively evenly distributed.

The number of companies in different stages of existence is roughly the same. The most are companies that have existed for 10-12 years, accounting for $28.40 \%$, and the least are companies that have existed for 3-6 years, accounting for $14.20 \%$. The overall sample survival time distribution must be relatively uniform, so the sample data has a certain analytical significance.

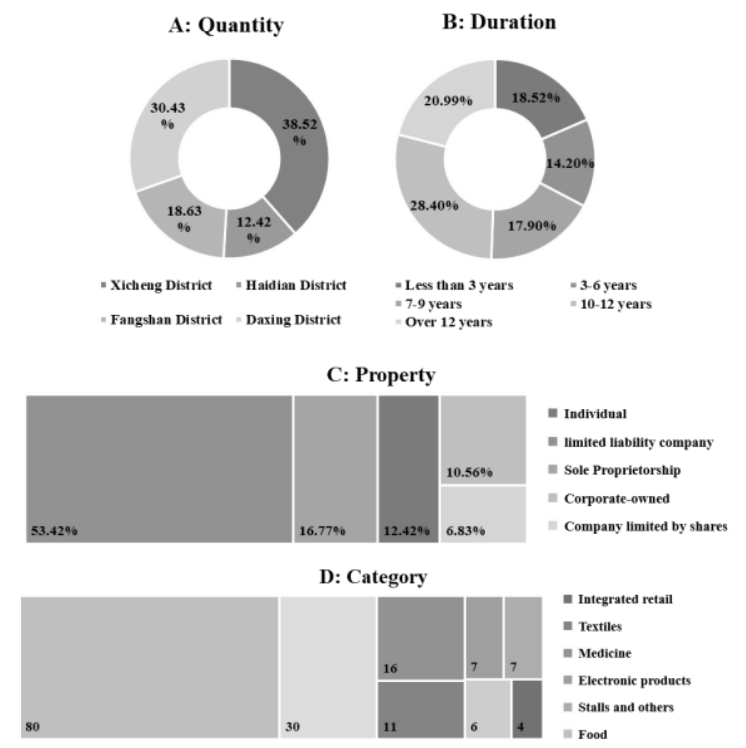

Figure 3: The surveyed company's area, business scope, duration, and nature of the company

\section{Data Analysis}

\subsection{Data Test: Normality, Reliability and Validity Test}

The parameter estimation method of structural equation model requires that the value of each variable should obey the normal distribution. If the condition of observing the normal distribution of variables can not be met, it will lead to the standard deviation of high estimation and underestimation of parameter estimation. Therefore, the model operation can only be carried out when the studied variables satisfy the normality.

In this paper, the single sample Kolmogorov-Smirnov test method of SPSS is adopted. The results show that all available problem options meet the normality requirements, and the data can be used for the next analysis. The results show that Cronbach's Alpha is greater than 0.8 before and after standardization, which indicates that the reliability of data is very high, which can be used for follow-up research.

In order to ensure the structural validity of the questionnaire, this paper uses common exploratory factors to analyze the structural validity of the questionnaire. Before implementing factor analysis, the correlation among variables should be analyzed. The KMO values of variables are $0.872,0.839$, 0.935 and 0.895 respectively, which shows that they are very suitable or suitable for factor analysis. In addition, Bartlett's sphericity test rejected the original hypothesis, indicating that they are suitable for factor analysis. The graphic display of specific results is limited to the inconvenient display, which can be obtained from the author.

\subsection{Questionnaire Factor Analysis}

In this paper, the cognitive and driving factors of corporate social responsibility are analyzed by exploratory factor analysis, and the performance of corporate social responsibility and enterprise performance scale are analyzed by confirmatory factor analysis. The principal component analysis method is used to explain and name the factors when extracting the factors. Among them, social responsibility cognition explores attitude cognition factor and meaning cognition factor, and corporate social responsibility driving force explores external pressure and internal appeal factor. The explanation rate of market, community, employees and environment in the implementation of corporate social responsibility is $79.91 \%$. The explanation rate of enterprise economic, social and environmental performance factors reached $76.61 \%$.

\section{3 "Cognition - Performance - Performance" Structural Equation}

\subsubsection{Model solving}

In this paper, AMOS 22.0 software is used to build the model and solve the model. The specific solution path diagram is as Figure 4 shows.

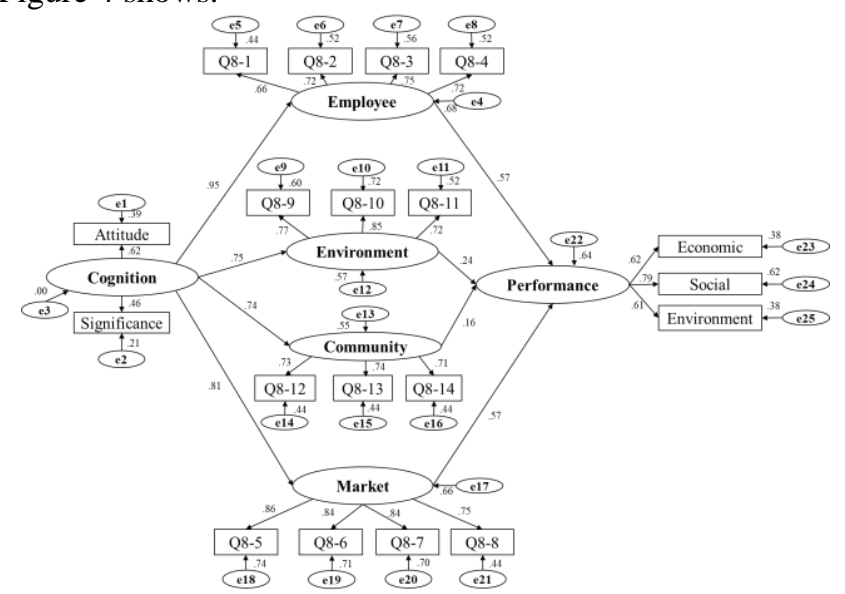

Figure 4: Structural equation path diagram and standardized output results 
Fitting test. Table 2 gives the "chi-square/degree-of-freedom ratio", RMSEA, GFI, CFI, goodness-of-fit and other relevant values, among which the three core evaluation indicators (chi-square/degree-of-freedom ratio, RMSEA, CFI) all show the fitting of this model.

Table 2: Evaluation effect of structural equation mode

\begin{tabular}{|c|c|c|c|c|}
\hline Fitting & Index & Model & Standard & Compliance with \\
\hline \multirow{2}{*}{$\begin{array}{c}\text { Absolute } \\
\text { fitting } \\
\text { index }\end{array}$} & $\chi^{2} / d f$ & 0.0005 & $<3.00$ & Accord with \\
\cline { 2 - 5 } & GFI & 0.916 & $>0.9$ & Accord with \\
\cline { 2 - 5 } $\begin{array}{c}\text { Relative } \\
\text { fitting } \\
\text { index }\end{array}$ & NFI & 0.038 & $<0.05$ & Accord with \\
\cline { 2 - 5 } & CFI & 0.929 & $>0.9$ & Accord with \\
\hline
\end{tabular}

Parameter verification. In the previous structural model, the value of the error variance is all non-negative, and the standard error of the variable does not produce an excessively large value. In addition, the absolute values of regression coefficients are all smaller than the required critical value of 0.95 , and finally the model passed the parameter test.

Table 3: Path coefficient and corresponding test value

\begin{tabular}{|c|c|c|c|c|}
\hline \multicolumn{3}{|c|}{ Path } & Estimate & S.E. \\
\hline Environmental & $\leftarrow$ & Cognitive & $0.75^{* * *}$ & 0.324 \\
\hline Community & $\leftarrow$ & Cognitive & $0.74^{* * * *}$ & 0.322 \\
\hline Market & $\leftarrow$ & Cognitive & $0.81^{* * * *}$ & 0.303 \\
\hline employees & $\leftarrow$ & Cognitive & $0.95^{* * * *}$ & 0.333 \\
\hline Performance & $\leftarrow$ & employees & $0.57^{* *}$ & 0.146 \\
\hline Performance & $\leftarrow$ & Market & 0.67 & 0.072 \\
\hline Performance & $\leftarrow$ & Community & 0.16 & 0.076 \\
\hline Performance & $\leftarrow$ & Environmental & $0.24^{* *}$ & 0.086 \\
\hline
\end{tabular}

\section{Conclusions and Recommendations}

According to the results of the structural equation model of "Cognition-Fulfillment-Performance", this paper draws the following conclusions: (1) Entrepreneur's social responsibility cognition can significantly promote the fulfillment of social responsibility; (2) Different social responsibility fulfillment has different effects on enterprise performance. Under the current situation, only the fulfillment of employee responsibility and environmental responsibility will have a positive impact on the performance of retail enterprises, while market responsibility and community responsibility have no such effect. In view of the existing conclusions, this paper puts forward the following suggestions.

(1) Enterprise managers take the initiative to improve the sense of responsibility and cultivate the image of corporate social responsibility. Empirical data prove that positive managers' attitudes promote the fulfillment of corporate social responsibility, thereby improving corporate performance. This result eliminates all kinds of concerns for enterprises to undertake social responsibility. It is suggested that managers should integrate the concept of social responsibility into corporate strategy, create an atmosphere of corporate social responsibility from top to bottom, deepen the good impression of stakeholders on enterprises, and enhance the public image of enterprises.

(2) Enterprises selectively fulfill their social responsibilities. Considering the limited resources of SMEs, this article recommends that companies focus on fulfilling their employee and environmental responsibilities, and fulfill their market and community responsibilities as appropriate. Companies are fair and just in recruiting, appointing, dismissing, and promoting; reducing discrimination; choosing environmentally friendly and recyclable packaging; providing high-quality products; investing funds to fulfill community responsibilities while increasing exposure.

(3) The government plays a guiding role and uses the media to improve the exposure rate of outstanding enterprises. The government should play a guiding and supporting role in the process of fulfilling the social responsibility of small and medium-sized enterprises, and take the initiative to pay attention to the implementation and development of the social responsibility of small and medium-sized enterprises, so that enterprises can feel the role of the government. Through the introduction of measures and publicity with tools, we can create a good atmosphere for fulfilling social responsibilities. Increase the media exposure to local outstanding enterprises.

(4) The market should smooth the transmission mechanism of "responsibility-performance" and establish a fair competitive market environment. Relevant departments should strictly enforce the law, resolutely crack down on counterfeiting, commercial fraud, tax evasion and fraud, establish a fair competitive market environment, reduce various frictions and "noises" of market responsibility and community responsibility in the process of influencing enterprise performance, and smooth the transmission mechanism of "responsibility-performance".

\section{References}

[1] Oliver, S. "The Social Responsibility of Management: The Philosophy of Management," London: Sir Issac Pitman and Sons Ltd, 1924.

[2] Bowen, HR. "Social Responsibility of the Business," New York: Harper, 1953.

[3] Chai Zhimin, Liu Xiaoying, Li Fuzhong, "Cost-benefit analysis of social responsibility investment of SMEs," Accounting of Chinese Township Enterprises, X, pp. 120-121, 2009.

[4] Li Cuiqin, "On the content of corporate social responsibility,” Management, XVII, pp.181-181, 2011.

[5] Yu Yiyi, "Research on the Decision Model of Corporate Social Responsibility Investment," Business Accounting, XIV, pp.58-60, 2013.

[6] Shen Hongtao, Chen Tao, Huang Nan, "Involuntary or willing: Analysis of the event history of social responsibility report authentication decision," Accounting Research, III, pp.79-86+96, 2016.

[7] Bai Guiyu, Xu Xiangyi, Liu Hongzheng, "Strategic decision-making tendency and contingency thinking of corporate social responsibility based on changes in financial performance," Accounting Monthly, XXXVI, pp.3-9, 2017.

[8] Lu Yumei, Yu Xin, Zhou Jianying, "Research on the decision-making mechanism of the new generation employees' social responsibility behavior in private 
enterprises," Macroeconomic Research, VII, pp.141-150, 2018.

[9] Tuzzolino F, Armandi B R. "A Need-Hierarchy Framework for Assessing Corporate Social Responsibility,' Academy of Management Review, VI(1), pp.21, 1981.

[10] Ran yibo, "Survey of corporate social responsibility in seven countries-investigation report of American human resources ethics association (SHRM)," Journal of WTO Economics, V, pp.66-68, 2007.

\section{Author Profile}

Haitao Zhao studied at Beijing Technology and Business University from 2016 to 2020 and obtained a bachelor's degree in economics. $\mathrm{He}$ is currently studying at the University of International Business and Economics for postgraduate studies. 